\title{
A STUDY OF AN ONSHORE WIND FARM DESIGN IN BÜYÜKADA REGION ${ }^{*}$
}

\author{
Emre LEBLEBİCIOĞLU ${ }^{1}$, Tanay Sıdkı UYAR ${ }^{2}$ \\ ${ }^{1}$ Marmara University, Department of Mechanical Engineering, Istanbul, Turkey, \\ leblebicioglu.emre@gmail.com; ORCID: 0000-0001-9974-3645 \\ ${ }^{2}$ Beykent University, Department of Mechanical Engineering, Istanbul, Turkey, \\ tanayuyar@beykent.edu.tr; ORCID:0000-0002-0960-1203
}

\begin{abstract}
All world is in a clean energy transition from fossil fuels to renewables. Every year the renewable power capacity grows, while the growth of fossil fuel-based power capacity decreases. Wind farms $(W F s)$ have an important role to accelerate the clean energy transition. That is why the WFs should be designed and planned well before the installation of them. The well-designed WFs give a higher capacity factor than the WFs that are not planned well. There are many WF design parameters that must be considered such as wind measurement, site analysis, environmental limitations etc. Hence there are wind farm design tools, which are used in the wind power sector and WindSim is one of these tools. In this study, an onshore wind farm was designed in the Büyükada region via WindSim. According to the results of this study, the feasibility of this WF and other energy system options were discussed and the necessary suggestions were emphasized.
\end{abstract}

Keywords: Wind Farm, Wind Power Plant, Wind Energy, WindSim, Büyükada

\section{INTRODUCTION}

Global warming or climate change threats humanity in many aspects. The growth of greenhouse gases in the atmosphere is the main reason for this inevitable fact. Growing population, energy production, industry and transportation sector are the main carbon sources that contribute to global warming. Among these sectors, the power sector leads the $\mathrm{CO} 2$ emissions by $40 \%$ [1]. This significant amount of emissions can reduce the energy transition from fossil fuels to renewable. Thus, the decreasing carbon foot-step is significant to deal with climate change. The main goal of the Paris Agreement is to keep the growth of global average temperature to under $2{ }^{\circ} \mathrm{C}[2]$.

Renewables showed a significant growth in the power sector in 2019 despite the COVID-19 pandemic. According to the REN 21 Global Status Report, the renewable power capacity grew more than $200 \mathrm{GW}$ in 2019 and this is the highest renewable capacity growth ever. Moreover total renewable power capacity reached $2588 \mathrm{GW}$ in 2019 worldwide. Solar and wind power are responsible for this notable growth as the previous year. While the solar power capacity increased to $627 \mathrm{GW}$ from $512 \mathrm{GW}$, the wind power capacity increased to $651 \mathrm{GW}$ from $591 \mathrm{GW}[3]$.

\footnotetext{
${ }^{1 *}$ Received: 05.01.2021 - Accepted: 10.01.2021

DOI: 10.17932/EJEAS.2021.024/ejeas_v01i1001
} 
Even though there is a huge jump in the renewable power sector, the world is still dependent on fossil fuels in power generation. The share of electricity production by fossil fuels is around $80 \%$ worldwide [3]. However, the capacity expansions of renewable power plants are getting bigger than fossil fuel power plants. Wind and solar are two sources that showed the significant amount of growth last years.

However, the share of these sources in electricity production is not where expected yet. Because solar and wind are variable energy sources. When the wind blows and the sun shines, then the electricity is produced. Due to this reason, the capacity factor of wind and solar is relatively low compared with nuclear and natural gas. Wind power plants have a higher capacity factor than solar power plants due to the potential of electricity production at night time. By the developing technology, the capacity factor of wind farms is getting higher year by year. While the capacity factor of onshore wind farms is $34 \%$ in 2018 , this is expected to reach $58 \%$ in 2050 [4].

The wind power sector in Turkey is also growing. Turkey is a developing country, which aims to reach its own energy independence. That is why the long term energy policies of Turkey are based on domestic sources such as renewables and indigenous coal. Hence Turkey expands the renewable power capacity every year. The renewable power capacity of Turkey was $44588 \mathrm{MW}$ in 2019, while it was $42215 \mathrm{MW}$ in 2018. The installed wind power capacity makes up $7591 \mathrm{MW}$ and $17 \%$ of the total renewable capacity in 2019 [5].

According to the development plan of Turkey, wind farms have an important role to achieve the energy goals of Turkey and the deployment of renewable energy systems. Furthermore, Turkey has considerably high wind energy potential with an annual mean speed of 2,6 m/s and a wind power density of 25,8 W/m2 [6]. According to Melikoglu's study, the feasible and theoretical wind power potential of Turkey is $48000 \mathrm{MW}$ and 88000 MW respectively [6].

Figure 1 shows the change in wind power capacity from 2008 to 2019. The installed power capacity has been cumulatively increasing throughout the years. Moreover, the share of wind in the electricity production was $8 \%$ of the total electricity production in 2018 [7].

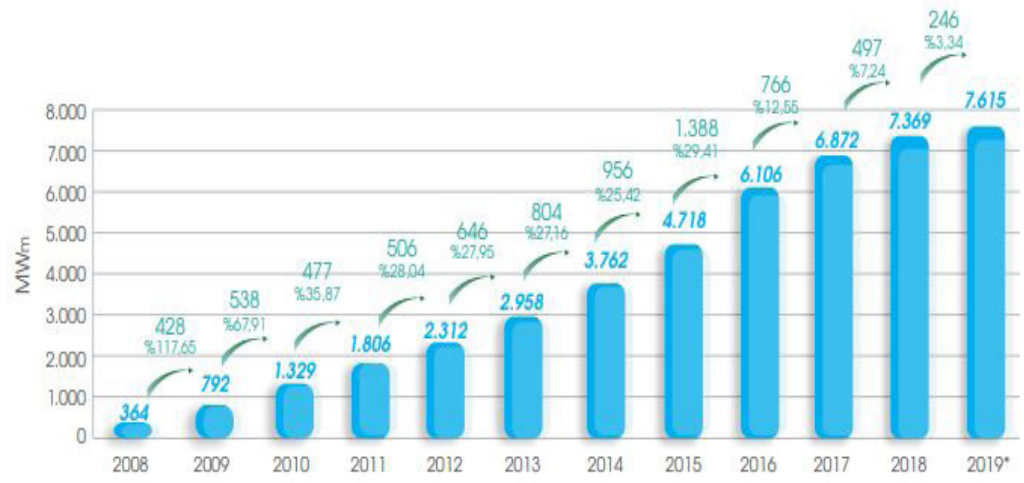

YILLAR / YEARS

Figure 1. The capacity of Cumulative Installed Wind Power Plants in Turkey by years [7] 
The WFs requires considerably large areas to be constructed. Furthermore, the WFs cannot be installed everywhere, only in the areas, which have efficient wind power potential. There are many parameters to design a WF efficiently such as site analyzing, wind assessment, micrositing. Thanks to the technology, there are some specific software where WFs can be designed. WindSim, wind farm design software is one of this software. In this study, an onshore wind farm was designed and results were obtained for Büyükada via WindSim. This study aims to show the estimated electricity production and the capacity factor of the planned wind farm in the region of Büyükada.

\section{MATERIAL AND METHODS}

In this study, Büyükada is the selected region for performing a wind farm design. Büyükada is an island, which is located on the Marmara Sea, Istanbul. Electricity access and transmission are challenging for the islands due to the limited area and transportation drawbacks. Central power plants such as coal, nuclear and natural gas are not environmentally feasible for small islands like Büyükada. A wind power plant is one of the best solutions to contribute to the electricity supply of Büyükada.

There are more or less 7500 people who live in Büyükada and this population changes for a year. Because Büyükada is a touristic destination for foreign and Turkish people. Thus, the electricity demand shows the changes. The estimated annual electricity consumption of Büyükada is approximately 3,65 GWh. Furthermore, Büyükada is a relatively small island whose size is $5,4 \mathrm{~km} 2$. This means that there is no large area to build a wind farm [9].

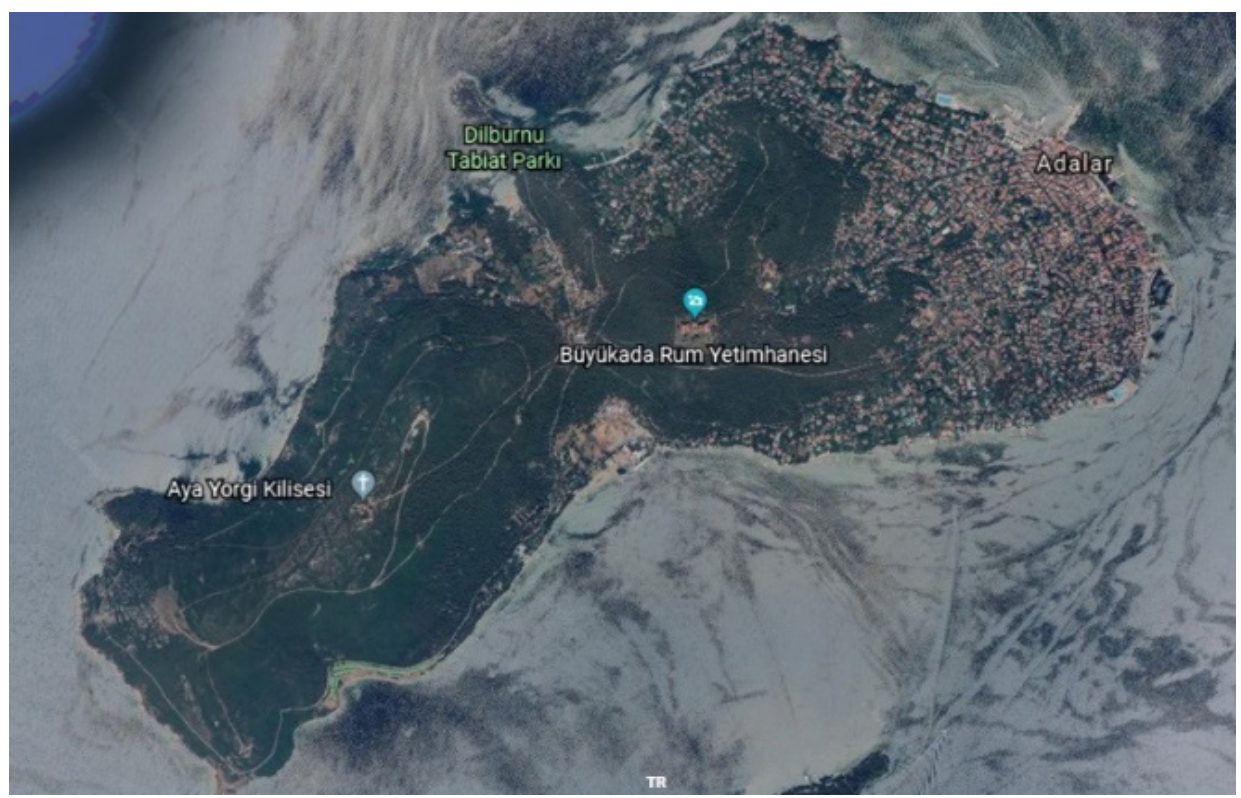

Figure 2. Top View of Büyükada 


\subsection{WIND POWER POTENTIAL OF TURKEY}

Turkey has a notable wind power potential with an annual mean wind speed of $2,6 \mathrm{~m} / \mathrm{s}$ and a power density of $25,8 \mathrm{~W} / \mathrm{m} 2$ [10]. Nowadays, this potential is used to generate electricity by wind turbines. Wind turbines are located in an area where wind speed and power density are high and consist of wind farms. Theoretical and feasible wind energy potential in Turkey was estimated $88.000 \mathrm{MW}$ and 45.000 MW respectively, according to Melikoglu's study [6].

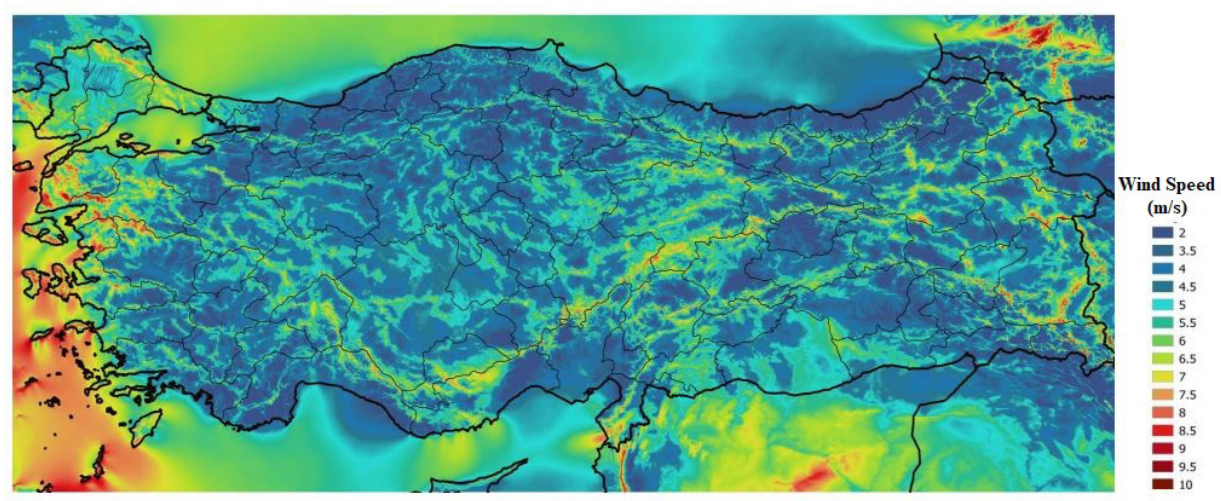

Figure 3: Wind energy potential atlas (WEPA) [10]

Figure 2 shows the wind speed distribution of Turkey at a $100 \mathrm{~m}$ elevation. Marmara region and the western side of Turkey have a relatively high wind power potential. Figure 3 also shows the wind power density distribution of Turkey

Sulukan study shows that wind-based electricity generation would reach 286,75 PJ in 2025 and the installed capacity was foreseen 29870 MW in the same year [11].

\section{WIND FARM DESIGN IN BÜYÜKADA}

WindSim is a modern Wind Farm Design Tool (WFDT) and it is used to optimize the annual power production and to design the wind farms. This is performed by computing numerical wind fields over the digitalized terrain and this is known as micrositing.

Windsim combines with wind speeds and wind directions for climate conditions to find an optimal position for each wind turbine of the WF. Climatology data is mostly obtained by on-site wind measurements. However, this data can be also found by meteorological models. WindSim can process both of these datasets.

WindSim has different modules to design a WF. These models can be also considered stages to get the estimated power generation data. These modules are Terrain, Wind Fields, Objects, Results, Wind Resources and Energy. In this section, the wind farm design for Büyükada is introduced by these 6 modules. [11]

\subsection{TERRAIN}

The first step of starting the feasibility analysis is to create the digital terrain model of Büyükada. Windsim gives the digital terrain model by using data of the geographical location. The elevation and roughness data, which are important for the wind farm design can be observed by this model. Figure 3 shows the elevation levels of Büyükada, while Figure 4 shows the roughness data. 


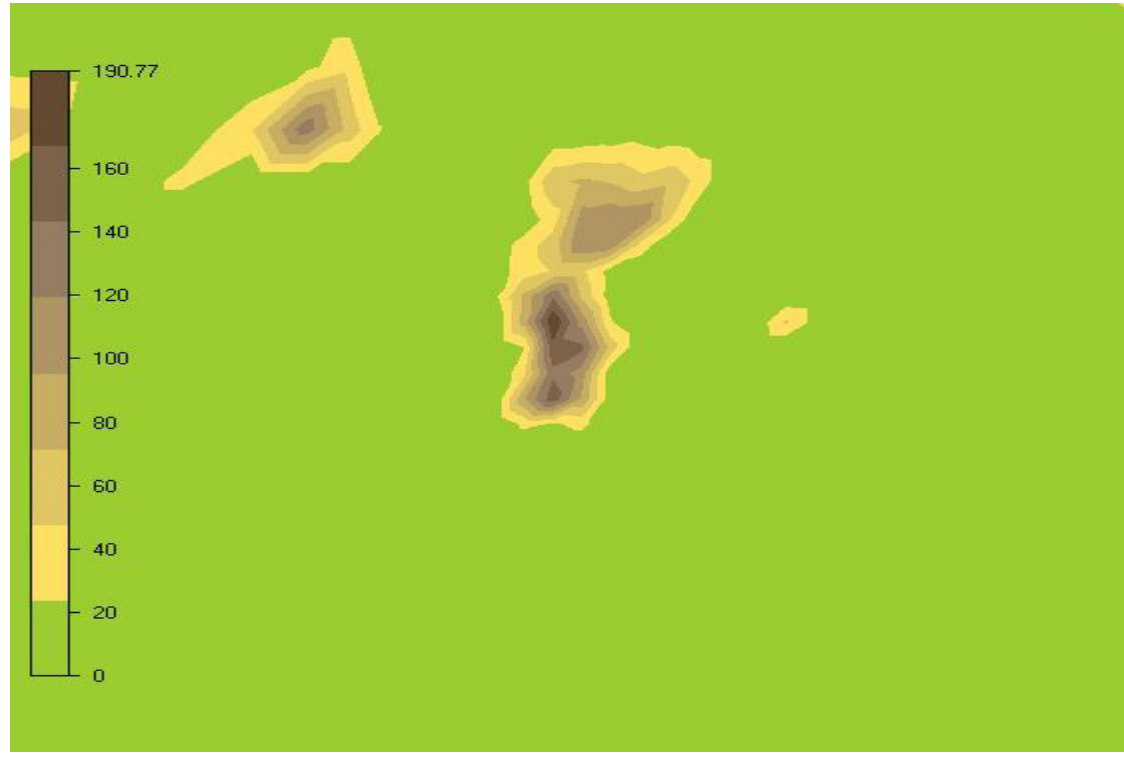

Figure 4. Digital terrain model - Elevation (m)

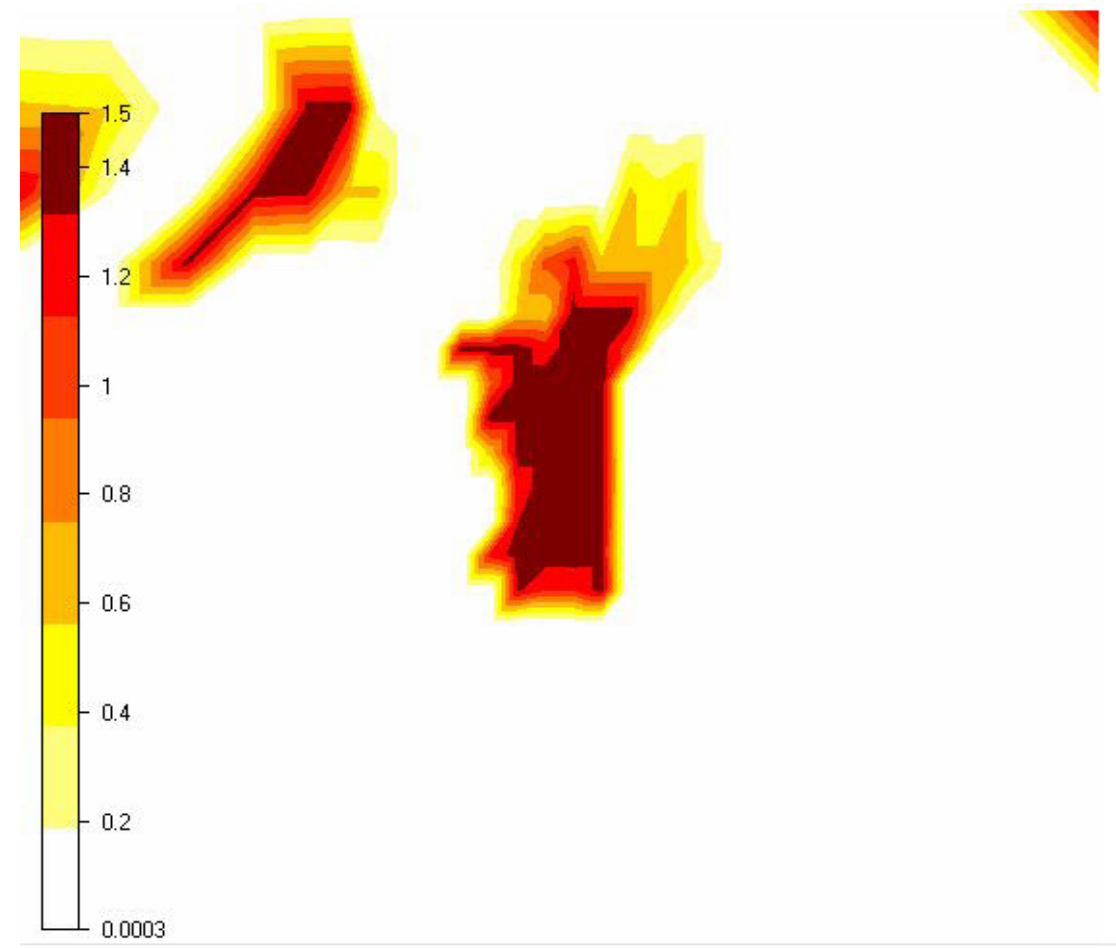

Figure 5. Digital terrain model - Roughness height (m). 


\subsection{WIND FIELDS}

The module of wind fields is run on a basis of Reynolds Averaged Navier-Stokes equations (RANS) and the k-epsilon model is applied as a turbulence closure. In this module, the results of the digital terrain model are used. Due to the non-linear equations, the solution of the module is iterative. The solution is resolved until a converged result is obtained. 3D wind speed values on the terrain can be observed in Figure 5.

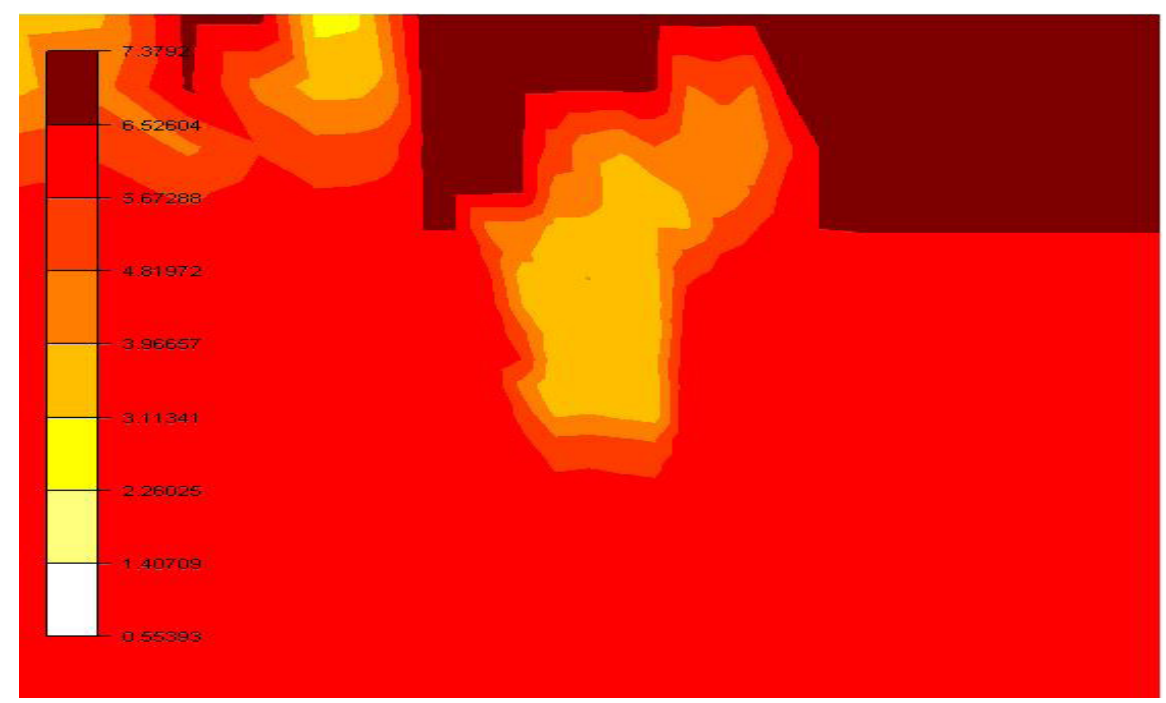

Figure 6. Convergence monitoring: Wind speed 3D $(\mathrm{u}, \mathrm{v}, \mathrm{w})$

\subsection{OBJECTS}

In the module of objects, the features of wind turbine and climatology data are used to locate the wind turbines in the best optimal area. Climatology data contains data of the hourly wind speed, wind direction during a year. These parameters are significant to simulate and calculate the estimated annual wind power generation. Gamesa G90 wind turbine was selected for this study. The power capacity of this turbine is $2 \mathrm{MW}$ and two of these turbines were located on the terrain by considering the results of the terrain and wind field modules.

Table 1: The Datasheet of Gamesa 2 MW G90 Wind Turbine [12].

\begin{tabular}{ll}
\hline & Gamesa 2 MW G90 \\
\hline Manufacturer: & Gamesa \\
Rated Power: & $2000 \mathrm{~kW}$ \\
Cut-in wind speed: & $3,0 \mathrm{~m} / \mathrm{s}$ \\
Rated wind speed: & $11,0 \mathrm{~m} / \mathrm{s}$ \\
Cut-out wind speed: & $21,0 \mathrm{~m} / \mathrm{s}$ \\
Diameter: & $90 \mathrm{~m}$ \\
Hub height: & $100 \mathrm{~m}$ \\
Swept area: & $6362 \mathrm{~m}^{2}$ \\
\hline
\end{tabular}


The wind farm park layout can be seen in Figure 6. The wind turbines are located in a row with a specific distance from each other. This distance is generally 5 or 7 times the length of wind blades. Figure 6 also shows the wind measurement station behind the wind turbines. This location represents where the climatology data was obtained.

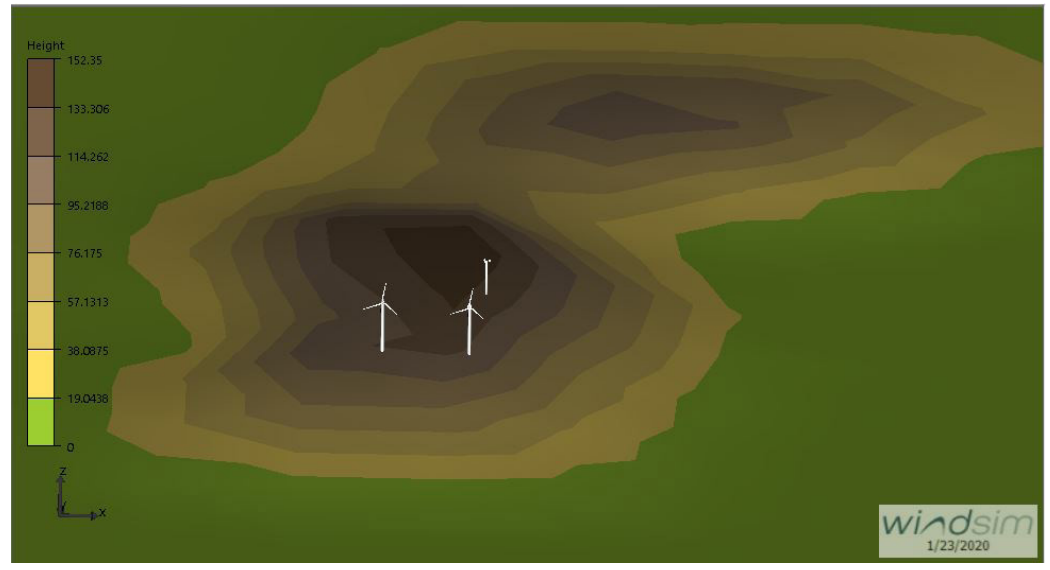

Figure 7. Park Layout of Wind Farm

\subsection{RESULTS}

The module of results is a kind of database where simulations of the wind field are saved. In this module, variables and 2D planes in the database can be extracted. Possible wind speed on the wind turbines can be observed in Figure 7. To sum up, this module shows the result of climatology data on the selected area and illustrates data that is imported to the software.

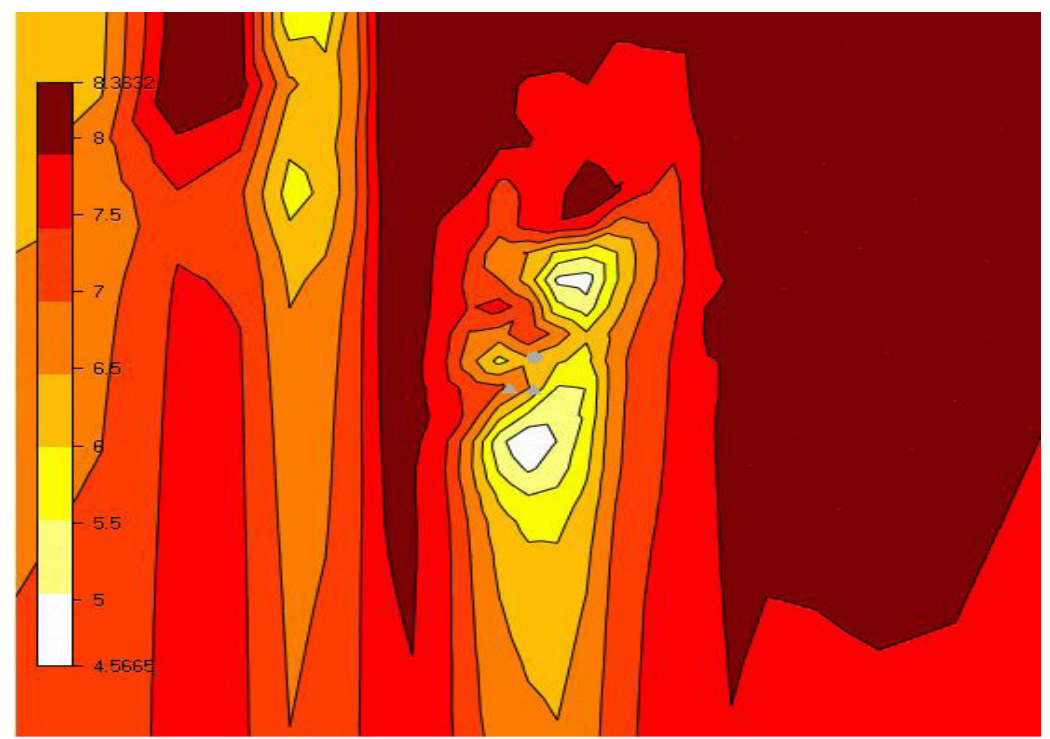

Figure 8. Wind speed 3D $(\mathrm{u}, \mathrm{v}, \mathrm{w})$ 
Wind speed values in the three dimensions can change in the software while adding different parameters into the software. Climatology data, turbulence and wind blockages can change the speed of the wind that blows on the wind turbines. This speed also changes in the module of wind resources.

\subsection{WIND RESOURCES}

The module of the wind resources shows the final wind speed and power density values after analyzing the parameters that can change the wind, such as turbulence regions, wind blockages, roughness, elevation etc. In this module, the potential of power generation can be observed and the power density and the wind speed regions on the digital terrain can be seen in Figure 8 and Figure 9 respectively.

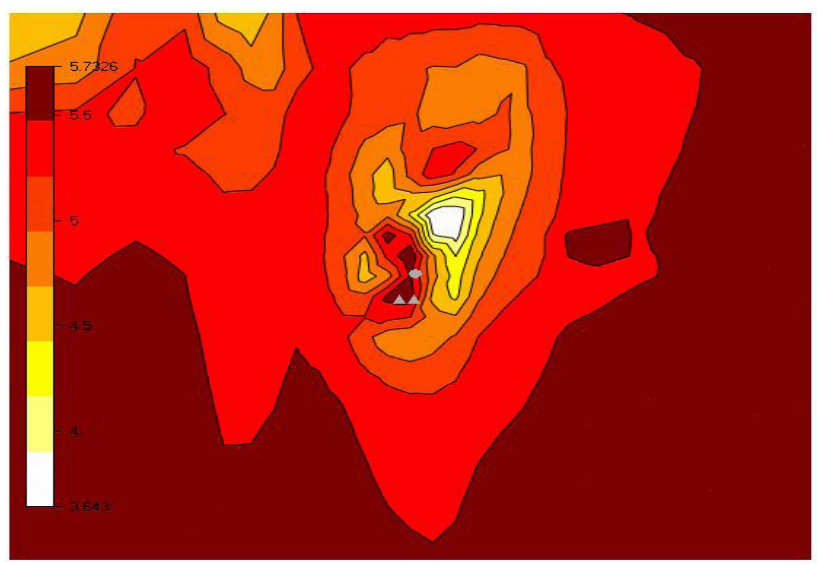

Figure 9. Wind speed 3D (u,v,w), Not Normalized

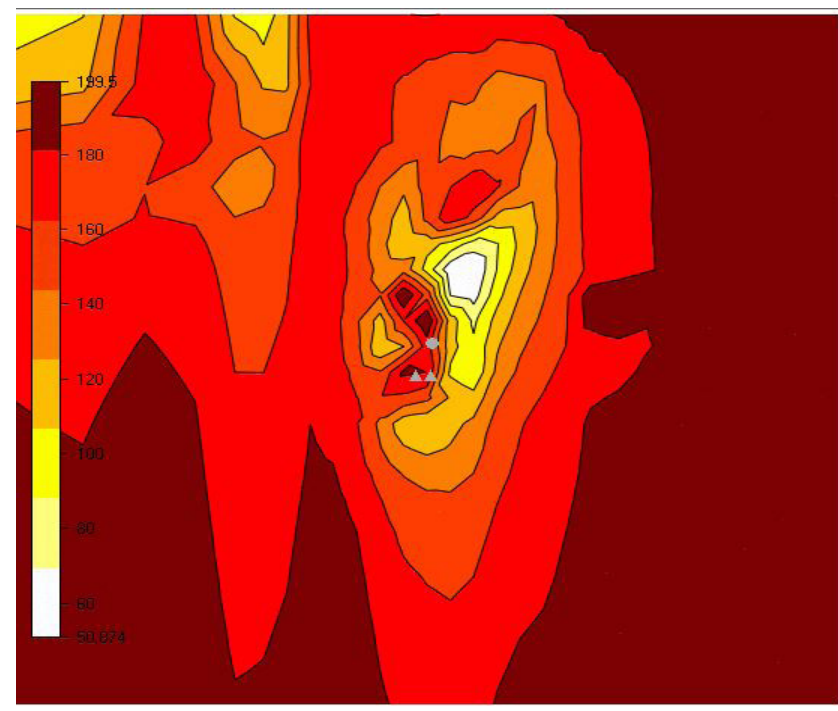

Figure 10. Power Density $\left(\mathrm{W} / \mathrm{m}^{2}\right)$ 


\subsection{ENERGY}

The final module of the WindSim is the energy module. This module gives the estimated power generation by the wind turbines. This is called annual energy production (AEP). AEP is calculated by using the data from previous modules. In this module, the annual electricity production by the wind farm can be observed and the capacity factor can be calculated. AEP can be seen in Figure 10 along with other parameters such as wind speed, power density etc.

\begin{tabular}{|c|c|c|c|c|c|c|c|c|c|c|}
\hline name & $\begin{array}{l}\text { power } \\
\text { (kW) }\end{array}$ & $\begin{array}{c}\text { hub height } \\
\text { (m) }\end{array}$ & $\begin{array}{l}\text { density } \\
\left(\mathrm{kg} / \mathrm{m}^{*} 3\right)\end{array}$ & $\begin{array}{l}\text { wind } \\
\text { speed } \\
(\mathrm{m} / \mathrm{s})\end{array}$ & $\begin{array}{l}\text { wind speed } \\
\text { including } \\
\text { wake losses } \\
(\mathrm{m} / \mathrm{s})\end{array}$ & $\begin{array}{l}\text { power density } \\
\left(W / m^{*} 2\right)\end{array}$ & $\begin{array}{l}\text { gross AEP } \\
\text { (MWh/y) }\end{array}$ & $\begin{array}{l}\text { AEP with } \\
\text { wake } \\
\text { losses } \\
\text { (MWh/y) }\end{array}$ & $\begin{array}{c}\text { wake loss } \\
\text { (\%) }\end{array}$ & $\begin{array}{c}\text { full load } \\
\text { hours } \\
\text { (h) }\end{array}$ \\
\hline wecs1 & 2000 & 100.0 & 1.225 & 6.20 & 6.20 & 250.3 & 4146.5 & . & . & 2073.2 \\
\hline wecs2 & 2000 & 100.0 & 1.225 & 6.27 & 6.27 & 262.7 & 4261.2 & - & - & 2130.6 \\
\hline All & 4000 & . & - & - & - & . & 8407.7 & . & - & 2101.9 \\
\hline Mean & - & . & 1.225 & 6.23 & 6.23 & 256.5 & . & . & - & . \\
\hline \multicolumn{11}{|c|}{ Reference production at climatology position: vortex time_series $80 \mathrm{~m}$} \\
\hline ref.. & 2000 & 100.0 & 1.225 & 6.21 & - & 251.8 & 4152.3 & $\cdot$ & $\cdot$ & 2076.1 \\
\hline ref.. & 2000 & 80.0 & 1.225 & 6.02 & - & 226.8 & 3846.5 & - & - & 1923.2 \\
\hline
\end{tabular}

Figure 11. Energy production based on the frequency table.

The estimated annual electricity production of the wind farm is more or less 8407,7 $\mathrm{MWh} / \mathrm{y}$ as is seen in Figure 10. Recall that the average annual electricity consumption of Büyükada is $3650 \mathrm{MWh}$. The wind farm can able to supply this demand. However, the wind is a variable source, which means the wind cannot be enough to spin turbines all the time. When the electricity demand is high in the daytime, wind turbines may not be enough to supply this due to the low wind speed. That is why the wind farm should support the energy storage systems and solar PV systems can be also considered.

The capacity factor of this system is calculated by using the annual electricity production and the installed power capacity. The estimated capacity factor of this WF is calculated by the following formula.

The capacity factor of this WF is calculated as shown below.

$$
\text { Capacity Factor }=\frac{8,4 M W h / y}{\left(24 \frac{\text { hours }}{\text { day }}\right) *(365 \text { days }) * 4 M W} * 100=24 \%
$$

The planned WF in Büyükada region is an onshore WF. The average capacity factor of onshore WFs is $34 \%$ in 2018. The capacity factor, which was calculated for this study is much lower than the average capacity factor. The reason for this situation is about geographical and environmental limitations. Because the WF cannot be placed in the residential zone and the size of Büyükada is limited. Moreover, the chosen area in Büyükada has high area roughness. For these reasons, the onshore wind power plants may be unfeasible for Büyükada. However, they should be still considered or the offshore WFs can be evaluated. In this study, the design of onshore WF in Büyükada was considered and analyzed. 


\section{CONCLUSION}

This study shows that the wind farm can supply the electricity demand of Büyükada. However the electricity consumption changes during the day. The electricity demand reaches the maximum level day time and goes to the minimum level at the night time. That is why the wind power plant may not supply the electricity demand every hour since wind is the variable source. Therefore the designed wind farm should be supported by the energy storage systems. When the wind does not blow enough at the peak time. The storage system can supply the electricity need. The electricity production of the wind farms is high at night. Thereby the excess electricity is stored at night, when the electricity demand is low.

There are many types of electricity storage systems, which can be integrated into the WFs, such as the pumped hydro, compressed air storage, and utility-scale batteries. To sum up, the energy storage system is a necessity for $100 \%$ renewable energy systems. Hence Büyükada also needs a well-planned storage system.

Electric vehicles can be another efficient storage option for islands. There are electric vehicles in Büyükada, which can be used for vehicle to grid (V2G) technology. Vehicle to grid means that the electric vehicle act like a storage unit. When electric vehicles do not run, they can give the electricity to the power grid by the batteries within.

In this study, a wind farm design for Büyükada was showed via WindSim and results were obtained to analyze the feasibility of this wind farm. This designed WF is onshore. Offshore wind farms are another option for islands and should be also considered. However, the main focus of this study is the onshore WF design. Furthermore, some design parameters should be taken into account. For instance, the electrical distribution between WF and transformers. Moreover, the noise calculations of wind turbines can be also evaluated by WindSim. Although the environmental conditions were considered in this study, the detail of noise calculation was ignored. The wind turbine placement was performed with a specific distance between the residential zone and the WF (Approximately $1 \mathrm{~km}$ distance).

To sum up, the WFs should be planned well and they should be supported by other energy systems. Moreover, the roughness, the elevation, on-site wind measurement and other geographical details should be analyzed to obtain a more efficient WF.

As a result, Windsim and similar wind analysis software are significant for the preinstallation of a wind farm. These types of software tools must be used for designing wind power plants. This study is now a unique example for designing onshore WF on an island using WindSim. 


\section{REFERENCES}

[1] IEA, Global energy-related CO2 emissions by sector, IEA, Paris https://www.iea.org/ data-and-statistics/charts/global-energy-related-co2-emissions-by-sector.

[2] Bluebook citation: Paris Agreement to the United Nations Framework Convention on Climate Change, Dec. 12, 2015, T.I.A.S. No. 16-1104.

[3] REN21. 2020. Renewables 2020 Global Status Report (Paris: REN21 Secretariat). ISBN 978-3-948393-00

[4] IRENA (2019). Future of wind: Deployment, investment, technology, grid integration and socio-economic aspects

[5] IRENA (2020).Renewable capacity statistics 2020 International Renewable Energy Agency (IRENA), Abu Dhabi

[6] Melikoğlu, M. (2016). "The Role of Renewables and Nuclear Energy in Turkey's Vision 2023 Energy Targets: Economic and Technical Scrutiny". Renewable and Sustainable Energy Reviews, 62, pp. 1-12.

[7] TWEA (2019). “Turkish Wind Energy Statistic Report 2019”. Turkish Wind Energy Association

[8] Adalar Belediyesi. “İçemiz Sayfası-Büyükada”. Retrieved from http://www.adalar. bel.tr/ilcemiz-sayfasi/buyukada.html

[9] Republic of Turkey Ministry of Energy and Natural Resources (2018). "Info BankRenewable Energy-Resources-Wind-Wind Energy Potential Map (REPA)". Retrieved from https://enerji.gov.tr/eigm-resources

[10] Sulukan E. (2018). “An analysis of centennial wind power targets of Turkey”. Turkish Journal of Electrical Engineering \& Computer Science (2018) 26: 2726 - 2736

[11] Meissner C. (2017). WindSim Getting Started 11th Edition. WindSim AS.

[12] GAMESA, Turbines-Gamesa G90-Datasheet. Retrieved from https://en.windturbine-models.com/turbines/763-gamesa-g90 